\title{
Virtual fencing technology to intensively graze lactating dairy cattle. II: Effects on cow welfare and behavior
}

\section{Megan Verdon, ${ }^{*} \odot$ Adam Langworthy, $\odot$ and Richard Rawnsley}

Tasmanian Institute of Agriculture, Faculty of Science, Engineering and Technology, University of Tasmania, Tasmania, Australia, 7320

\begin{abstract}
Virtual fencing technology uses a neckband-mounted device to deliver an audio cue when an animal nears a virtual boundary that is set via a global positioning system, followed by an electrical stimulus if it crosses the boundary. The flexibility offered by this technology could revolutionize grazing management on dairy farms, but its application and effects on lactating dairy cattle have not been assessed. This experiment reports on the effects of an electric or a virtual front-fence on dairy cow behavior and welfare. Two temporally separated treatments were applied to a herd of 30 multiparous cows. Cows were provided an estimated 14 to $15 \mathrm{~kg}$ of dry matter/cow of fresh pasture in a new paddock every $24 \mathrm{~h}$. From d 1 to 10 cows were grazed using a conventional electric front-fence (control treatment) and from d 14 to 23 they were grazed using a virtual front-fence (eShepherd, Agersens Pty Ltd.). Cows were trained to the technology from d 11 to 13 . The milk production and live weight of individual cows were recorded daily. Cortisol concentrations were obtained from milk samples collected from individual cows on $3 \mathrm{~d}$ during each of the control and the virtual fence grazing periods, plus the first day of training. From d 6 of the experiment, 6 focal cows were fitted with a RumiWatch (Itin + Hoch GmbH) noseband sensor to monitor grazing and ruminating time, and 8 focal cows were fitted with an IceTag (IceRobotics Ltd.) sensors to monitor activity. Milk production, live weight, and the time cows spent standing and lying did not differ between the electric and virtual fence periods. Milk cortisol concentrations, activity, and the times spent ruminating and grazing were comparable between the electric and early virtual fence periods (i.e., d 1-3 with a virtual fence). However, at d 4 to 6 with a virtual fence, activity (steps taken and motion index) and time spent grazing were lower, and time spent ruminating was greater, compared with an electric fence. Further,
\end{abstract}

Received October 15, 2020.

Accepted February 17, 2021.

*Corresponding author: megan.verdon@utas.edu.au least significant difference tests suggest milk cortisol concentrations were higher at d 5 with a virtual fence than at $\mathrm{d} 8$ with an electric fence and d 1 with a virtual fence. We conclude there is no evidence of behavioral and welfare effects of virtual fencing on dairy cows in the days immediately following implementation of the technology in a simple intensive grazing regimen, but a longer study is required to fully elucidate effects beyond this period.

Key words: associative learning, cortisol, shock, stress, time budget

\section{INTRODUCTION}

Virtual fencing technology uses a neckband-mounted device to deliver an audio cue when the animal approaches a global positioning system (GPS) defined virtual boundary (e.g., Campbell et al., 2019a,b; Lo$\max$ et al., 2019). An electrical stimulus is delivered by the device if, following the audio cue, the animal walks beyond the virtual boundary, but not if it stops walking or turns back. Over time, the animal learns to associate the audio cue with the pending electrical stimulus unless it changes its behavior, and increasingly responds to the audio cue alone. In this way, virtual fencing works similarly to electric fencing in that it is the cognitive realization by the animal that it cannot penetrate the fence without consequences, rather than the physical properties of the fence, that ultimately keeps it contained within the fence's boundaries (Stookey, 2010). Research using experimental prototypes of automated virtual fencing technology (eShepherd, Agersens Pty Ltd.) show that cattle rapidly learn the association between audio and electrical stimuli, and the number of electrical stimuli delivered declines over days (Campbell et al., 2019a,b; Lomax et al., 2019). This experimental prototype has also been used to prevent groups of 10 Angus heifers from accessing a riparian zone for $10 \mathrm{~d}$ (Campbell et al., 2019b) and to graze a group of 12 dry dairy cows for $6 \mathrm{~d}$ (Lomax et al., 2019). However, the application of virtual fencing technology to intensively graze lactating dairy cattle and to larger group sizes has not been demonstrated. 
It is common for dairy cattle to be housed outdoors and graze a predominantly pasture diet in temperate climates that occur in New Zealand and southern Australia. Pasture consumption (tonnes of dry matter per hectare) is a key driver of farm profitability in these systems and has been optimized over the years in part by increasing stocking rates (Stafford and Gregory, 2008; Chapman et al., 2014). Continued intensification of pastoral dairy production with more animals per unit of land has become environmentally and socially unsustainable (e.g., Clay et al., 2020). The implementation of grazing regimens that support the natural ingestive, digestive, and social behavior of cows may increase pasture consumption without increasing stocking rate (Verdon et al., 2018). For example, periodically providing portions of fresh pasture as cows trickle back to the paddock from the dairy could result in more equitable pasture intake, particularly in large herds (Dias et al., 2019). Implementation of more complex grazing regimens such as this has been impeded by costs associated with increased labor and fencing requirements (Anderson et al., 2014). Emerging technologies such as virtual fencing removes these barriers, and thus has the potential to revolutionize the management of grazing cattle (discussed by Campbell et al., 2019b).

New husbandry technologies and livestock management systems must maintain or improve animal welfare to be ethically acceptable (Lee et al., 2018). Acute stress is expected when animals are undergoing avoidance learning (Freire, 2010), but this learning is essential to successful operation of virtual fencing technology. The stress response should be minimal once animals have learned to avoid the electrical stimulus and this restores predictability and controllability to their environment (Lee et al., 2018). Recent research by Campbell et al. (2019b) found no difference in the fecal cortisol metabolite concentrations of groups of 8 Angus steers kept in 6-ha paddocks with a static electric tape or virtual fence, and fecal cortisol metabolite decreased over the 4 -wk observation period for animals in both treatments. In comparison to beef cattle, intensively grazed dairy cows are kept at high stocking densities, are frequently moved across the pastoral landscape and to the dairy, and are typically more habituated to humans and technologies. Thus, research relating to the animal welfare effects of virtual fencing technology in grazing dairy systems needs to be conducted on dairy cattle and intensive pastoral systems specifically, rather than to rely on data produced on beef breed cattle and more extensive grazing systems (Verdon et al., 2020).

This experiment aimed to determine the effects of an electric or a virtual front-fence on the behavior and welfare of dairy cows in early lactation, assessed using measures of milk cortisol concentrations, milk produc- tion, live weight changes, and behavior. We hypothesized that cow behavior and welfare, as indicated by the aforementioned metrics, would not differ between an electric or virtual front-fence. Our companion paper (Langworthy et al., 2021) presents data relating to the effectiveness of the virtual fencing technology when strip-grazing dairy cattle and implications for pasture utilization.

\section{MATERIALS AND METHODS}

\section{Ethical Statement}

All animal procedures were conducted with prior institutional animal ethics approval (University of Tasmania Animal Ethics Committee A0017449) under the requirement of the Tasmanian Animal Welfare Act (1993) in accordance with the National Health and Medical Research Council/Commonwealth Scientific and Industrial Research Organisation/Australian Animal Commission Australian Code of Practice for the Care and Use of Animals for Scientific Purposes. This experiment was originally designed to examine the application of virtual fencing technology to strip-graze lactating dairy cattle over $21 \mathrm{~d}$. It was discontinued after d 10 of grazing with the virtual front-fence (23 d since neckband fitting) due to the development of minor to moderate skin abrasions on the lower jaws of cattle. The development of skin abrasions has not been observed in other research or commercial trials using beef breed cattle or on nonlactating dairy cattle.

\section{Animals and Experimental Design}

This experiment was conducted over $23 \mathrm{~d}$ during mid-spring 2018 at the Tasmanian Institute of Agricultural Dairy Research Facility (TDRF; $41^{\circ} 08^{\prime} \mathrm{S}$, $145^{\circ} 77^{\prime} \mathrm{E} ; 155.0 \mathrm{~m}$ above mean sea level), Elliott, northwest Tasmania, Australia. Thirty early-lactation dairy cows of mixed breed were utilized (Friesian, Jersey, and Friesian $\times$ Jersey; parity range $2-7$, Bos taurus L.). All cows were naïve to virtual fencing technology. Cows were selected to minimize variation within the group in DIM (mean $\pm \mathrm{SD} ; 46 \pm 5 \mathrm{~d}$ ), daily milk production (mean $\pm \mathrm{SD} ; 26 \pm 3 \mathrm{~L}$ ), BW (mean $\pm \mathrm{SD} ; 474 \pm 35$ $\mathrm{kg}$ ), and BCS (mean $\pm \mathrm{SD} ; 4 \pm 0,8$-point scale). Cows were kept in a single herd, milked twice daily $(\sim 0730$ and $\sim 1430 \mathrm{~h}$ local time), and grazed perennial ryegrass (Lolium perenne L.; $\geq 80 \%$ )-based pastures for the duration of the experiment. A fresh pasture allocation was provided in a new paddock every $24 \mathrm{~h}$ following the afternoon milking. Paddocks used were randomly distributed across the TDRF milking platform, averaging $( \pm \mathrm{SD})$ a walking distance of $601 \pm 352 \mathrm{~m}$ from the 
milking parlor (range, 107 to $1,175 \mathrm{~m}$ ). On experimental d 20, cloprostenol (2 mL/cow of Ovuprost containing $500 \mu \mathrm{g}$ of the active ingredient; Bayer Australia Ltd.) was intramuscularly injected into each cow as part of the TDRF breeding program.

The perimeter of each paddock was defined by electric fencing with a mean voltage of $3.5 \mathrm{kV}$. A front-fence was used to separate the paddock into an inclusion zone (i.e., the area where animals could move freely) that contained the animals and an exclusion zone (i.e., the area where animals were being prevented from accessing) that contained fresh pasture and no animals. Inclusion zones had a mean $( \pm \mathrm{SD})$ area of $3,371 \pm 963 \mathrm{~m}^{2}$, length of $100 \pm 11 \mathrm{~m}$, and width of $34 \pm 9 \mathrm{~m}$. Exclusion zones always represented $>24 \%$ of total paddock area with an average area and length of 2,224 $\pm 936 \mathrm{~m}^{2}$ and $70 \pm 23 \mathrm{~m}$, respectively. Cows were allocated 14 to $15 \mathrm{~kg}$ of pasture $\mathrm{DM} / \mathrm{cow}$ per day and 1.8 to $2.7 \mathrm{~kg}$ of grain/cow per day that was offered in the dairy at milking. The nutritive value of pasture and grain and the methods used in the estimation of pasture biomass are detailed in Langworthy et al. (2021). Water was provided ad libitum via water troughs within the inclusion zone.

Two temporally separated treatments were applied to the herd of cows. From d 1 to 10, cows were strip-grazed using a conventional electric tape front-fence (control treatment) and from d 14 to 23 they were strip-grazed using a virtual eShepherd front-fence (virtual fence treatment; see following section for more details on the eShepherd technology). Training of cows to the eShepherd virtual fencing technology was conducted over $3 \mathrm{~d}$ between the control and virtual fencing grazing periods (d 11-13) in a 2.2-ha paddock (length $240 \mathrm{~m}$, width $91 \mathrm{~m}$ ) that was bordered by a 2-stranded galvanized electric fence. A virtual front-fence divided the training paddock so that the inclusion zone occupied $75 \%$ of the total paddock area, with the length of inclusion and exclusion zones 180 and $60 \mathrm{~m}$, respectively. Pasture biomass did not fall below 1,800 $\mathrm{kg}$ of $\mathrm{DM} /$ ha during the training period. At the conclusion of training all cows had interacted with the virtual front-fence (i.e., received at least one audio cue). Data on the number of stimuli delivered, time in the exclusion zone, and pasture utilization are presented in Langworthy et al. (2021).

\section{The eShepherd Neckbands}

The virtual fencing pre-commercial prototype (eShepherd, Agersens Pty Ltd.) system was used in this trial and has been described by Campbell et al. (2020). The neckband worn by the cattle consisted of a strap and hanging counterweight (total weight approximately 1.4 $\mathrm{kg}$ ) and a unit (approximately $725 \mathrm{~g}$ and dimensions: $170 \mathrm{~mm}$ length $\times 120 \mathrm{~mm}$ width $\times 140 \mathrm{~mm}$ height), positioned on top of the animal's neck. The cows wore eShepherd neckbands for the entire experiment. Each neckband device used uncorrected GPS fixes to determine the cow's proximity to virtual fences. The location and activation status of virtual fences was controlled by a cloud-based web interface, which communicated with eShepherd neckband devices via a wireless radio frequency link (base station). As a cow approached the virtual fence boundary the neckband device emitted a distinctive but nonaversive audio tone within the animal's hearing range. No electrical pulse was applied if the audio cue caused the cow to stop moving forward or turn away. If the cow continued to move through the virtual fence into the exclusion zone, the unit delivered a short, sharp electrical pulse sequence in the kilovolt range. The intensity of the pulse stimulus delivered by the neckband was lower in energy than an electric fence. The precise values of the electrical pulse are commercial and confidential. This sequence of an audio tone followed by the electrical pulse was repeated if the cow continued to walk through the fence line and further into the exclusion zone. No stimuli were applied if the cow turned around to re-enter the inclusion zone. This algorithm design functions to "herd" the animals back out of the exclusion zone after entry. Stimuli were not applied if cow movement occurred above a specified velocity (values are commercial and confidential). As a safety feature to limit the maximum number of consecutive pulses an animal could receive, the device entered standby mode and stimuli were not applied for a specified time frame (values are commercial and confidential) if an individual received a specified number of pulses within a specified timeframe (values are commercial and confidential). The neckband algorithm also included a grazing function. The natural behavioral pattern of grazing can mimic the correct response by the animal to the neckband cues of movement forward and stopping at an audio cue. Therefore, if an animal received 3 consecutive audio cues in the exclusion zone while still moving forward paired with stopping, an electrical pulse was applied. A base station was set up adjacent to the trial paddock that communicated with the neckbands, and animal activity was able to be monitored in real time through an online user-interface. All neckband cues were stored on a removable SD card within the device for later download.

\section{Climatic Measures}

Average ambient air temperature $\left({ }^{\circ} \mathrm{C}\right)$, wind speed $(\mathrm{km} / \mathrm{h})$, relative humidity $(\%)$, solar radiation $\left(\mathrm{W} / \mathrm{m}^{2}\right)$, and rainfall $(\mathrm{mm})$ were recorded by an Environdata 
Weather Station Pty Ltd. (v1.7.1) located at TDRF. Temperature-humidity index (THI) was calculated as $\mathrm{THI}=(1.8 \mathrm{~T}+32)-[(0.55-0.0055 \mathrm{RH}) \times(1.8 \mathrm{~T}$ - 26)], where $\mathrm{T}=$ air temperature $\left({ }^{\circ} \mathrm{C}\right)$ and $\mathrm{RH}=$ relative humidity (\%) (Ravagnolo et al., 2000). Daily temperature, wind speed, relative humidity, and solar radiation averaged (mean $\pm \mathrm{SD}$ ) $9.4 \pm 2.1^{\circ} \mathrm{C}$ (range 5.8 to $13.3^{\circ} \mathrm{C}$ ), $6.4 \pm 2.0 \mathrm{~km} / \mathrm{h}$ (range 3.5 to $10.8 \mathrm{~km} / \mathrm{h}$ ), $80 \pm 5.4 \%$ (68.6 to $88.5 \%$ ), and $156.1 \pm 34.3 \mathrm{~W} / \mathrm{m}^{2}$ (range 95.7 to $217.7 \mathrm{~W} / \mathrm{m}^{2}$ ). The THI averaged $49.9 \pm$ 3.3 (range 44.0 to 56.0). Precipitation was recorded on 4 control, 1 training, and 3 virtual fence experimental days. Rainfall on these days averaged $1.1 \pm 0.6 \mathrm{~mm}$.

\section{Measures Recorded}

Milk Cortisol. Milk samples were collected from individual cows during the afternoon milking on $3 \mathrm{~d}$ during the control period (electric fence d 5, 7, and 9), on $\mathrm{d} 1$ of the virtual fence training period $(14 \mathrm{~h}$ after training commenced; training $\mathrm{d} 1$ ), and $3 \mathrm{~d}$ during the virtual fence period (virtual fence d 1, 3, and 5). Milk cortisol concentrations reflect plasma cortisol accumulated over at least $8 \mathrm{~h}$ of milk synthesis before milking (Shutt and Fell, 1985; Verkerk et al., 1996, 1998). Thus, this sampling timeline was chosen to allow for a comparison of baseline cortisol concentrations under control conditions to the stress response during training and the initial introduction to grazing with a virtual front-fence, as well as an assessment of how quickly cows adjust to virtual fence grazing system over days.

Samples were frozen after collection until ready for analysis of cortisol concentrations. Skim milk was prepared and assayed by an externally contracted accredited laboratory (University of Western Australia, Perth, Australia) with a Bovine cortisol ELISA Kit (Assay Matrix Pty. Ltd.). Intra- and interassay coefficients of variation were 5.9 and $8.3 \%$, respectively.

Milk Production. The milk yield of each cow was automatically recorded at each milking for each day of the experiment using a DeLaval Alpro milk metering system (DeLaval International AB). Data from each milking were summed to obtain daily milk production for each cow (L/cow per day).

Live Weight. Cow live weight was measured twice daily as animals exited the milking parlor using automatic in race walk-over scales (DeLaval AWS100 automatic weighing system). The AWS100 software utilizes an algorithm that discounts recorded weights that differ greatly from the 7-d mean weights for individual animals (e.g., instances when more than one cow was on the platform at any one time). The data from each weighing were averaged to obtain cow live weight per day $(\mathrm{kg})$.
Behavior. A subset of cows were fitted with a RumiWatch noseband sensor, integrated into a halter $(\mathrm{n}=6$ cows; Itin + Hoch GmbH), or IceTag sensors, strapped to the hindleg below the hock $[\mathrm{n}=8$ cows; IceRobotics Ltd.; dimensions $(\mathrm{mm}) 95.0$ (height) $\times 85$ (width) $\times$ 31.5 (depth); weight $17.0 \mathrm{~g}]$, or both ( $\mathrm{n}=6$ cows). The same cows wore the devices from fitment until the experiment concluded. A delay in the delivery of these sensors postponed their fitting until d 4 of grazing with an electric fence (i.e., control grazing period). Cows were given $24 \mathrm{~h}$ after attachment to habituate to the sensors after which data were continuously collected for the remainder of the experiment. Only data related to the times that cows were in their paddocks were extracted from the RumiWatch and IceTag outputs. RumiWatch outputs allowed for the calculation of the percentage time grazing and ruminating per day. Overall activity levels (motion index, an indication of overall leg activity as measured in 3 dimensions), number of steps, and the percentage of time standing and lying per day were obtained from the IceTag data. These measures have been validated on cattle in pasture-based systems for their respective technologies (Ungar et al., 2018; Werner et al., 2018).

Four cameras (Hero5, GoPro Ltd.) were used to record behavioral responses of cows to audio and electrical stimuli on d 1,3 , and 5 of grazing with a virtual fence. These days were chosen to coincide with data relating to milk cortisol concentrations. Recording was undertaken after the morning milking (mean $\pm \mathrm{SD}, 4.9$ $\pm 0.59 \mathrm{~h}$ of recording). On the morning before recording days, cows were restrained in a cattle crush as they left the dairy and identification numbers sprayed on both of their sides using stock-spray. The behavioral response of cows to each audio and electrical cue were obtained from video records (see Table 1 for ethogram).

\section{Statistical Analysis}

Two cows were removed from the experiment and treated for mastitis at d 14 of the experiment (d 1 of grazing with the virtual fence). Pasture allocations were adjusted accordingly. Due to an error in the recording software, in $5 \%$ of cases milk production data were recorded for only one of the 2 daily milking events. These cases were treated as missing data.

All statistical analyses were carried out using the SPSS statistical software package (SPSS 26.0, SPSS Inc.) and the unit of analyses was the individual cow. Behavioral responses of cows to audio and electrical cues were subject to a descriptive analysis. All other variables were assessed for normality using visual methods (quantile-quantile plots and histograms) in combination with Shapiro-Wilks normality tests. Cortisol 
and live weight data underwent a logarithmic transformation before analysis so that residual variation was homogeneous between control and virtual fence treatment periods. The significance level $\alpha$ was set at $P \leq$ 0.05 . To aid with interpretation, raw data are presented with least squares means (LSM) [or transformed LSM (and backtransformed LSM)] \pm SEM presented in Supplemental Tables S1 and S2 (http://dx.doi.org/10 .17632/yjmcn2k75h.1).

Milk cortisol, milk production, and live weight data were analyzed using linear mixed models. The analysis of milk cortisol included the main effect of experimental day (d 5, 7, 9, 11, 14, 16, 18), whereas the main effects of treatment (control vs. virtual front-fence), day of treatment (1-10), and their interaction were included in the analysis of milk production and live weight. Spearman rank correlations and scatterplots were used to examine relationships between possible covariates [inclusion zone area, pre-grazing pasture biomass in paddock ( $\mathrm{kg}$ of $\mathrm{DM} / \mathrm{ha}$ ), estimated $\mathrm{kg}$ of DM allocated per cow, rainfall, solar radiation, THI, average milk production of the milking herd] and milk cortisol, milk yield, and live weight. No covariates were retained in subsequent analyses. Each linear mixed model accounted for repeated observations of cows over treatments (in the analysis of milk production and live weight) and day (all analyses) with a first-order autoregressive or diagonal matrix covariance, based on the structure with the lowest Akaike information criteria scores (see Supplemental Table S3, http://dx.doi.org/ 10.17632/yjmcn2k75h.1). In the case of a significant effect the least significant difference (LSD) test determined where LSM differed. Differences between cortisol LSM were assessed using the LSD test and a Bonferroni adjustment. The former has a low level of type II error, whereas the very conservative Bonferroni-adjusted error rate reduces the chance of type 1 error (Kaps and Lamberson, 2009).

There were changes in the behavior (activity, rumination) of cows following the cloprostenol injection at d 7 of virtual fence grazing (Supplemental Figure S1, http://dx.doi.org/10.17632/yjmen2k75h.1). Consequently, behavior beyond $\mathrm{d} 7$ with a virtual fence were not analyzed. Data obtained from the RumiWatch and IceTag sensors were grouped into three 3 -d periods for analysis. These periods were (1) d 6 to 8 of electric front-fence (called control period), (2) d 1 to 3 of virtual front-fence, and (3) d 4 to 6 of virtual front-fence. This allowed for differentiation between cow behavior during a period of adjustment to the virtual fencing technology and behavior after this period of adjustment. For each 3 -d period, the behavior data for individual cows were averaged per day to produce one value for each cow. Behavioral differences between the 3 periods were then analyzed using the nonparametric Friedman test. When a significant difference between periods was detected, post hoc analysis with the Wilcoxon signed-rank test were conducted.

\section{RESULTS}

\section{Milk Cortisol Concentrations}

Day had an effect on milk cortisol concentrations $\left(F_{6,125}=4.3, P=0.001\right.$; Figure 1$)$. The LSD and Bonferroni post-hoc tests identified an unexplained peak in cortisol at d 6 of the control grazing period (1.33 $\pm 0.59 \mathrm{ng} / \mathrm{mL}$ at d 6 compared with $0.89 \pm 0.54$ and $0.88 \pm 0.76 \mathrm{ng} / \mathrm{mL}$ at d 4 and 8, respectively; Figure $1)$. The LSD test found that cortisol concentrations at d 5 of grazing with a virtual fence were higher than at d 8 with an electric fence and d 1 with a virtual fence (Figure 1), but this was not significant when the Bonferroni adjustment was used. The variability between cows in cortisol concentrations increased over days with the virtual fence.

\section{Milk Production}

Milk production was not affected by treatment $\left(F_{1,166.2}=0.95, P=0.33\right)$, treatment day $\left(F_{9,351.6}=\right.$

Table 1. Ethogram of behaviors observed during grazing with the virtual front-fence (adapted from Verdon et al., 2020)

\begin{tabular}{|c|c|}
\hline Behavior & Description \\
\hline Stop & $\begin{array}{l}\text { Within } 1 \text { body length following stimulus delivery, cow stops moving and with all } 4 \text { feet on the ground remains } \\
\text { stationary for a minimum of } 5 \mathrm{~s}\end{array}$ \\
\hline Walk & Moving forward $1 \mathrm{leg}$ at a time with an even gait. Movement continues for more than 1 body length. \\
\hline Trot & $\begin{array}{l}\text { Moving forward at a pace that is faster than a walk. Head is typically held up. Movement continues for more than } 1 \\
\text { body length. }\end{array}$ \\
\hline Grazing & Head lowered to the ground and biting pasture \\
\hline Turn to the side & Full body turn of 45 to $135^{\circ}$ so cow is parallel (or almost parallel) to the virtual boundary \\
\hline Turn back & Full body turn of 135 to $215^{\circ}$ so cow is facing toward the inclusion zone \\
\hline Turn $360^{\circ}$ & Full body turn of $360^{\circ}$ or more \\
\hline
\end{tabular}




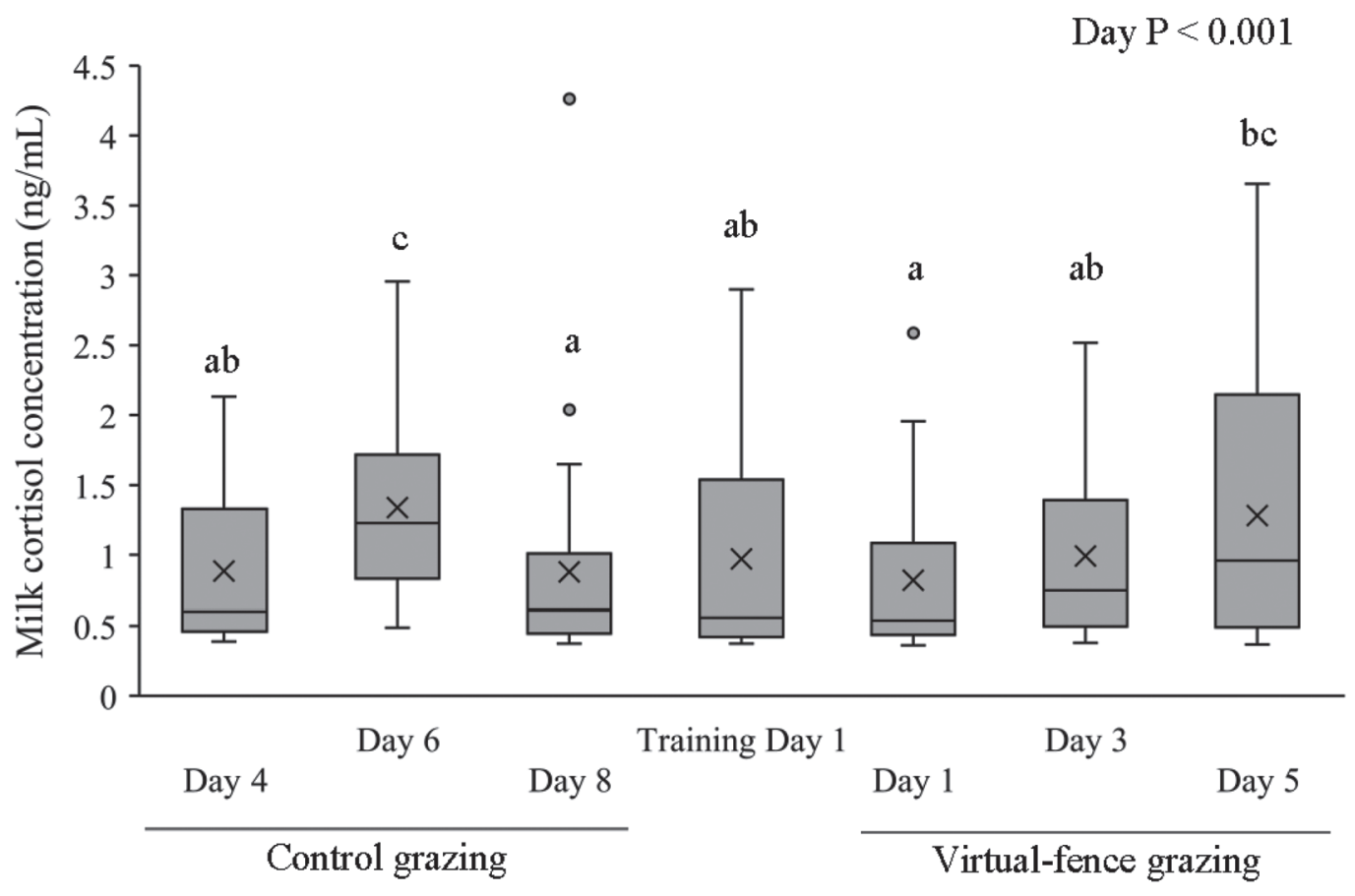

Figure 1. Boxplots of milk cortisol $3 \mathrm{~d}$ in the control grazing period, $1 \mathrm{~d}$ of the training period, and $3 \mathrm{~d}$ of the virtual fence grazing period. Differing letters $(\mathrm{a}-\mathrm{c})$ indicate where days differed $(P<0.05)$ following a least significant difference test. Boxplots show the median and the first and third quartiles (25 and $75 \%$ of data), with whiskers extending to the lowest and highest values that are not outliers (any value that is $1.5 \times$ the interquartile range). Means $(\times)$ and outliers $(O)$ are also presented.

$0.42, P=0.92)$, or their interaction $\left(F_{9,347.0}=1.3, P=\right.$ 0.24 ; Figure $2 \mathrm{~A})$. Cows produced $25.9 \pm 0.25$ and 26.2 $\pm 0.25 \mathrm{~L}$ of milk per day in the control and virtual fence grazing periods, respectively.

\section{Live Weight}

Live weight was not affected by treatment $\left(F_{1,172.0}\right.$ $=0.23, P=0.63)$, treatment day $\left(F_{9,326.9}=0.35, P\right.$ $=0.96)$, or their interaction $\left(F_{9,323.8}=0.39, P=0.94\right.$; Figure 2B). The average live weights of cows in the control and virtual fencing periods were $476 \pm 2.3$ and $479 \pm 2.4 \mathrm{~kg}$, respectively.

\section{General Activity}

The behavior of cows early during the virtual fencing period (i.e., d 1-3) was comparable to their behavior during the electric fence period (Figure 3). However, cows spent more time ruminating, less time grazing, and were less active (indicated by the motion index and number of steps) from d 4 to 6 with a virtual fence compared with an electric fence (Figures 3C-3F). The percent of time standing or lying did not differ between treatment periods (Figures 3A, 3B).

\section{Behavioral Response to Stimuli}

A GPS positioning error resulted in one animal receiving 9 audio and 2 electrical stimuli despite responding effectively (i.e., stop and turn, turn and walk, $360^{\circ}$ turns). A second cow received an audio cue when scratching her leg as she was lying. These cases are excluded from the following descriptive data.

Over the 3 recording days, behavioral responses to 107 audio cues and 13 electrical stimuli were observed in 25 of the 30 experimental cows. The vast majority of responses were effective ( $70 \%$ of responses to audio cue, $91 \%$ of response to electrical stimulus; Table 2). Of all the ineffective responses to the audio cue, $57 \%$ were observed at d 1, 27\% at d 3, and $8 \%$ at d 5 of grazing with the virtual fence (Supplemental Table S4, http:// dx.doi.org/10.17632/yjmcn2k75h.1).

Ten different behavioral responses were classified following the delivery of the audio cue. The most frequently observed responses to the audio cue were to turn and continue grazing (33\%), continue grazing (this ineffective response resulted in activation of the grazing algorithm, 24\%), and turn and walk away (21\%). Three different responses to the delivery of an electrical stimulus were recorded, with $73 \%$ of responses being 

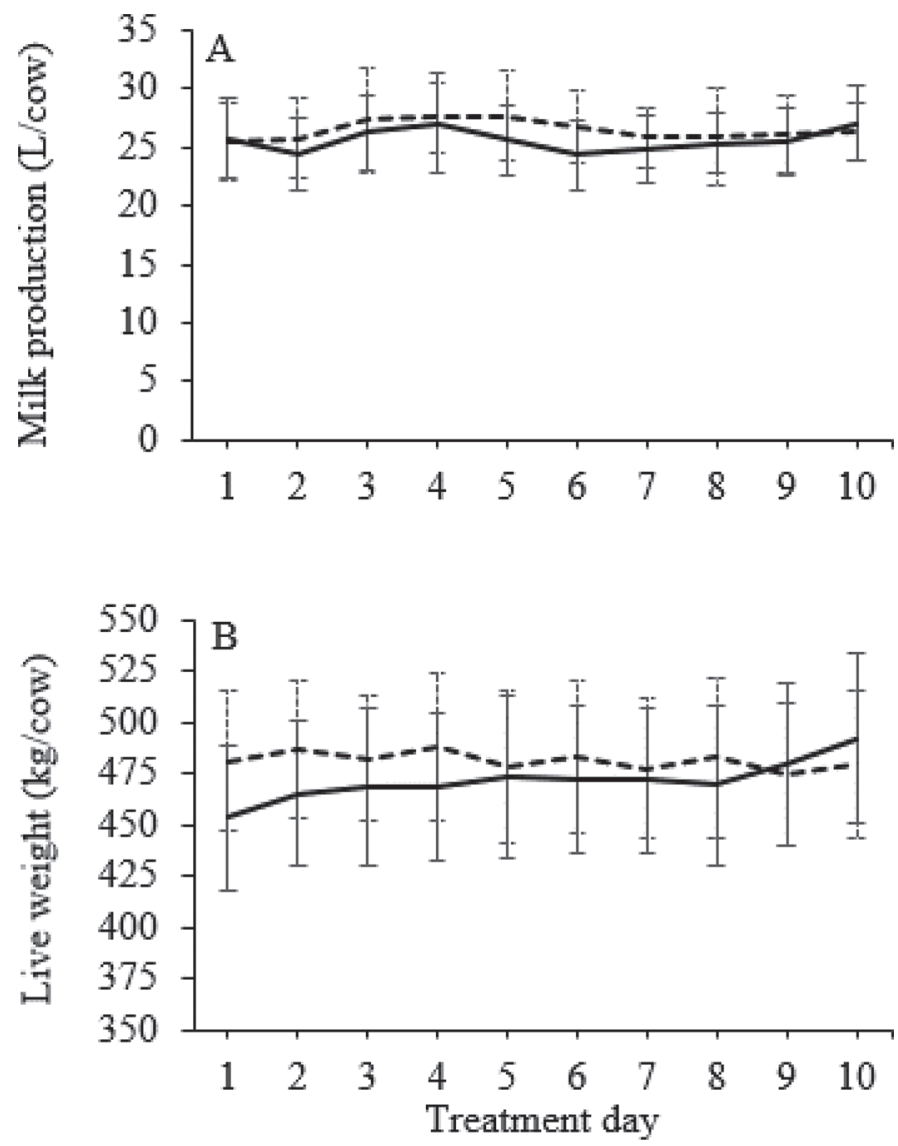

Figure 2. Changes in (A) milk production (L/cow) and (B) live weight $(\mathrm{kg} / \mathrm{cow})$ during $10 \mathrm{~d}$ of strip-grazing with an electric (solid line) or a virtual (dotted line) front-fence. Raw data $\pm 95 \%$ CI are presented.

to turn and walk or trot away, followed by $18 \%$ of responses to turn and graze (Table 2).

\section{DISCUSSION}

This is the first experiment to report on the application of virtual fencing technology to manage grazing lactating dairy cows. Data presented in this research show that dairy cows are successfully contained behind a virtual front-fence for $10 \mathrm{~d}$ with no effects on cow behavior or welfare early following implementation of the technology (see Langworthy et al., 2021, for data relating to virtual fencing technology efficacy). However, the longer-term implications for animal behavior and welfare are unclear.

\section{Acute Behavioral and Welfare Response}

Behaviors considered indicative of a high aversion to the stimuli delivered by the virtual fencing device were not observed in this experiment, such as cattle lunging or running through the virtual fence, lifting and shaking their heads, or bawling (Quigley et al., 1990; Anderson, 2007; Lee et al., 2007). The most frequently observed response to the audio cue was to turn and continue grazing, whereas the response to the electrical stimulus was to turn and walk away. In nearly $20 \%$ of cases, cows turned and continued grazing after receiving an electrical stimulus. Quigley et al. (1990) and Lee et al. (2008) similarly found steers to resume grazing within $10 \mathrm{~s}$ of receiving an electrical stimulus. These behavioral responses support experimental research showing that the receipt of electrical stimuli per se is not likely to be any more acutely stressful than common handling events (Lee et al., 2008).

Milk yield, live weight, and the time cows spent standing, lying, and drinking did not differ between the electric and virtual fence grazing periods, nor did milk cortisol concentrations, activity levels (motion index, steps), and the time spent ruminating and grazing differ between the electric and early virtual fence periods (i.e., d 1-3 with a virtual fence). These results suggest cows effectively learned the association between audio and electrical stimuli and were able to transfer these learnings to applied grazing conditions without affecting animal welfare. Indeed, cows in this research required an average of 3 audio events to form an association between audio and electrical stimuli, and before training there was a $65 \%$ chance that cows would ignore the audio cue and receive an electrical stimulus, but after training this chance had declined to $32 \%$ (see Langworthy et al., 2021). The chance of receiving an electrical stimulus reduced to $22 \%$ during grazing with a virtual fence, and cows were effectively contained by the virtual fence for over $99 \%$ of the time (see Langworthy et al., 2021). Accordingly, the majority of behavioral responses to the audio and the electrical stimuli in this experiment were categorized as effective (i.e., elicited no further stimuli; 67 and 91\%, respectively) and ineffective behavioral responses to the audio cue declined over days.

Cows in this experiment were noticeably more responsive to stimuli than heifers that were individually trained to virtual fencing technology using an earlier version of the eShepherd prototype (Campbell et al., 2018) or a manual training technology (Verdon et al., 2020) in feed attractant trials. Other research has identified a proportion of individually trained animals that ignore the audio cue and electrical stimuli (Campbell et al., 2018; Verdon et al., 2020), but this was not evident in the present experiment. The main value of individual testing lies in the provision of a scientific understanding of associative learning and the ability to identify factors that may affect the efficiency of associative learning, but applied research is required to assess the overall 
effectiveness or effects of the technology. Therefore, it is important to note that the data presented in this study relate to a simple grazing regimen that is unlikely to mimic the application of the technology on a commercial dairy farm. While our results demonstrate the potential of virtual fencing technology to manage the lactating dairy cow, further research is required to examine its use under more complex grazing regimens (e.g., multiple fence shifts per day with a front and back fence).

\section{Behavior and Welfare Beyond d 3 with a Virtual Fence}

There were some indications of increased physiological stress and disruption of behavioral time budgets from d 4 with a virtual fence. Milk cortisol concentrations reported in this experiment were generally comparable to baseline concentrations previously reported for cows in intensive pasture-based systems (e.g., $0.86-0.98 \mathrm{ng} /$ $\mathrm{mL}$, Hemsworth et al., 1989), with the exceptions of d 6 of grazing with the electric fence $(1.34 \pm 0.59 \mathrm{ng} /$ $\mathrm{mL})$ and $\mathrm{d} 5$ of grazing with the virtual fence $(1.28 \pm$ $0.91 \mathrm{ng} / \mathrm{mL}$ ). Cortisol concentrations were higher at $\mathrm{d} 5$ with a virtual fence compared with d 8 with an electric fence and $\mathrm{d} 1$ with a virtual front-fence when an LSD test was used to compare means, but not when the conservative Bonferroni adjustment was applied. This increase in cortisol concentrations was accompanied by reduced activity and time grazing at d 4 to 6 with a virtual compared with an electric front-fence. In contrast to the present experiment, Campbell et al. (2019b) found that cortisol metabolites in the feces of Angus steers decreased over $4 \mathrm{wk}$ of containment behind a single virtual fence. The diffusion of cortisol between blood and milk is almost instantaneous (Termeulen et al., 1981), whereas digesta intestinal transit times produce variable lag intervals between the elevation of plasma cortisol and subsequent elevation of fecal cortisol metabolite concentrations (Barrell, 2019). Nonetheless, both milk cortisol concentrations and fecal cortisol metabolite concentrations generally reflect plasma
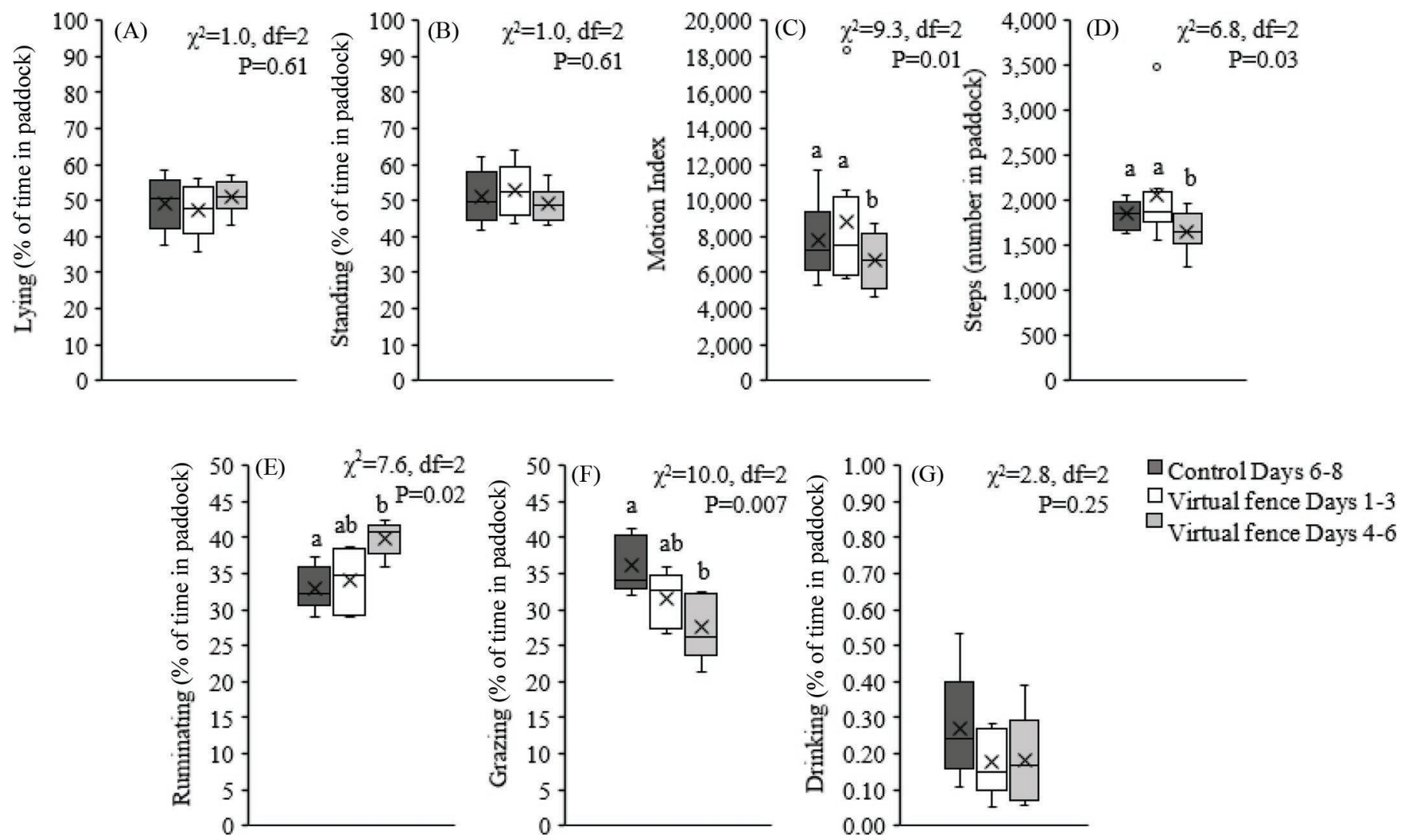

Figure 3. Boxplots of cow behavior obtained from IceTag $(\mathrm{n}=8$; panels A-D; IceRobotics Ltd.) and RumiWatch ( $\mathrm{n}=5$; panels E-G; Itin + Hoch $\mathrm{GmbH}$ ) sensors. Raw data are presented for each of three 3-d periods (x-axis): (1) d 6 to 8 of grazing with an electric front-fence (labeled control), (2) d 1 to 3 of grazing with a virtual front-fence, and (3) d 4 to 6 of grazing with a virtual front-fence. For each 3-d period, the behavior data for individual cows were averaged per day. Boxplots show the median and the first and third quartiles (25 and $75 \%$ of data), with whiskers extending to the lowest and highest values that are not outliers (any value that is $1.5 \times$ the interquartile range). Means $(\times)$ and outliers $(O)$ are also presented. Differing letters $(\mathrm{a}, \mathrm{b})$ indicate where 3 -day periods differed $(P<0.05)$. 


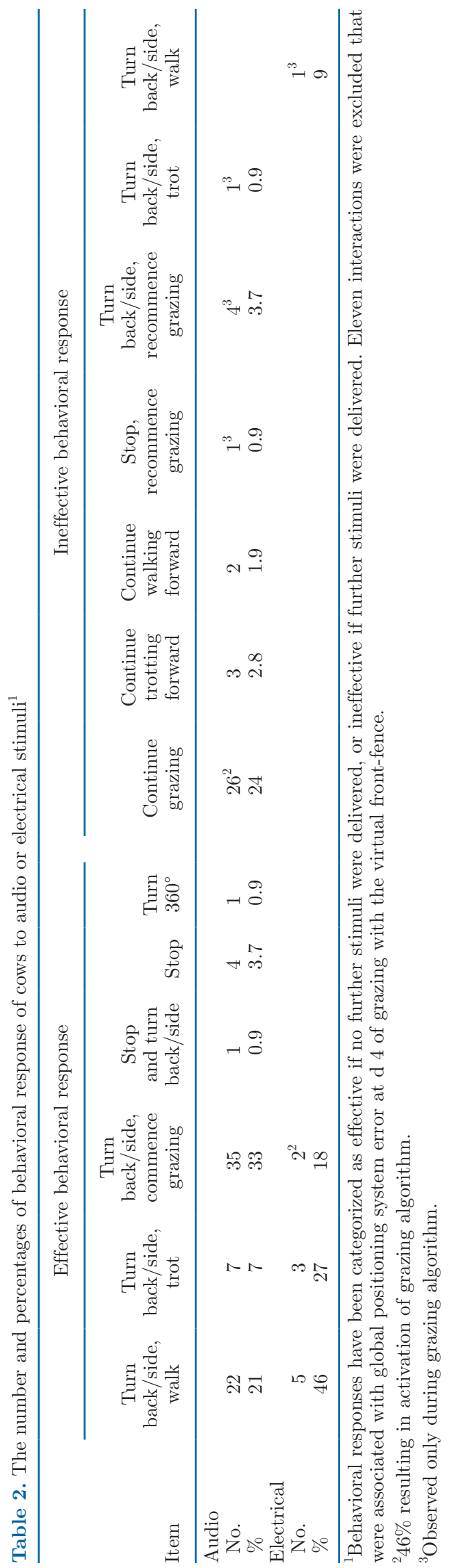

concentrations during the interval of milk synthesis or before defecation, making both biological media suitable for the detection of prolonged or chronic stress (Bremel and Gangwer, 1978; Verkerk et al., 1996, 1998; Palme, 2012).

The virtual fence was in a fixed location in the research by Campbell et al. (2019b), and because cattle use visual cues to learn the location of the virtual fence (e.g., Campbell et al., 2018; Lomax et al., 2019; McSweeney et al., 2020), this would have made it more predictable. By contrast, the daily provision of fresh pasture in a new paddock meant that the location of the virtual boundary had to be rediscovered each day of the present experiment. Such conditions may be associated with reduced environmental predictability, which has negative implications for animal welfare (Lee et al., 2018), regardless of whether the learning of the association between the audio cue and electrical stimulus has been effective. Both this experiment and McSweeney et al. (2020) found a decrease in grazing when dairy cows were confined behind a single virtual fence with no visual cues, and other research provides evidence that dairy cattle avoid the area of a paddock near where a virtual fence had been established (Lomax et al., 2019; McSweeney et al., 2020). Spatial and temporal consistency in the location and movements of the virtual boundary may be particularly important if virtual fencing is to be used to implement increasingly intense or complex grazing regimens in pastoral dairy farming (e.g., Verdon et al., 2018).

An alternative explanation for the changes in cortisol and behavior observed beyond d 4 with a virtual front-fence is that they are part of a normal adaptive response, meaning levels will return to baseline as animals adapt to the technology. Further, there is no obvious explanation for the increase in cortisol at d 6 of the electric fence treatment in the present experiment, other than that cows were in a paddock that ran adjacent to a public road for the period preceding milk collection, and across the road was a small group of calving cows. A similar extenuating circumstance may have contributed to the increase in cortisol at d 5 of virtual fence grazing, although none have been identified.

The skin abrasions observed on the jaws of cattle in the present experiment have not been observed in other research on beef breeds (Campbell et al., 2018, 2019a,b) or nonlactating dairy cattle (Lomax et al., 2019). The reduction in time spent grazing with a virtual compared with an electric front-fence may be associated with an avoidance of the behavior attributed to the skin abrasions, rather than a response to the technology per se. The same can be said of the increase in milk cortisol concentrations over the virtual fence grazing period, although there was no difference in 
cortisol levels of animals that did and did not develop injuries. The eShepherd protoype used in this experiment was designed for extensively grazed cattle and may need to be modified for use in intensive pastoral production systems. The development of skin abrasions and subsequent premature cessation of this experiment limit our ability to draw conclusions regarding the effects of virtual fencing on dairy cow welfare. Clearly longer-term research is essential to fully elucidate any animal welfare impacts of virtual fencing technology for livestock in intensive pastoral production systems. Ideally such research would include herd level replication, although we acknowledge the logistical difficulties in conducting large pasture-based dairy studies, which often makes such replication infeasible.

The reduction in time spent grazing from d 4 to 6 with a virtual front-fence aligns with the findings of Langworthy et al. (2021) of reduced pasture utilization with a virtual compared with an electric fence, but are contradicted by the fact that no changes in milk production or live weight were detected in this experiment. As discussed by Langworthy et al. (2021), the cows in this experiment grazed a pasture of higher average ME during the virtual compared with the electric frontfence period. Thus, the total energy intake of cows was comparable between the periods despite the reduction in pasture consumed.

\section{Individual Variability}

Variation between cows in milk cortisol concentrations increased during training and over days grazing with a virtual front-fence. Many studies have reported variation between cattle in associative learning of the audio cue and electric stimulus (Campbell et al., 2019b; Lomax et al., 2019; Verdon et al., 2020; Langworthy et al., 2021). This variation may, in part, be due to physiological differences between animals (Ralph and Tilbrook, 2016). Alternatively, Verdon et al. (2020) hypothesized that differences between heifers in the efficiency of associative learning are due to differences in the salience of the audio cue, the aversive nature of the electrical stimulus, or the animal's internal state (e.g., motivation to feed). Incomplete learning could also result in some animals in the group receiving a higher number of stimuli than others. In addition to variation in learning efficiency and perception of the aversive stimuli, individual animals may differ in their ability to adapt to the technology (e.g., coping styles; Koolhaas et al., 2010). The relationships between the efficiency with which individual cows learn the association between audio cue and electrical stimulus and their welfare and performance when managed with virtual fencing technology requires investigation.

\section{CONCLUSIONS}

Virtual fencing technology has the potential to revolutionize grazing management of the lactating dairy cow. This experiment found no effects of virtual fencing technology on the behavior or welfare of cows in the days following implementation of the technology. There were some indications of increased stress and disruption of behavioral time budgets from d 4 with a virtual fence, but milk production was not affected. A longer study period is required to fully elucidate any animal welfare impacts of virtual fencing technology for lactating dairy cattle managed in intensive pastoral production systems.

\section{ACKNOWLEDGMENTS}

This research was funded by the Australian Commonwealth Government Department of Agriculture and Water Resources as part of its Rural R\&D for Profit Programme, grant number 15-02-019. Thanks to Nathan Bakker, Steven Boon, Steven Emmett, Carlton Gee, Desmond McLaren, Bradley Millhouse, Benjamin Noble, Amy Potter, Oliver Radford, Thomas Snare, and Avril Stewart (Tasmanian Institute of Agriculture) for their support in operating this project, and to Bronwyn Stevens, Sally Haynes, Cameron Ralph, and Andrew Rhyder (Agersens Pty Ltd.) for technical support with the eShepherd system. The authors have not stated any conflicts of interest.

\section{REFERENCES}

Anderson, D. M. 2007. Virtual fencing-Past, present and future. Rangeland J. 29:65-78. https://doi.org/10.1071/RJ06036.

Anderson, D. M., R. E. Estell, J. L. Holechek, S. Ivey, and G. B. Smith. 2014. Virtual herding for flexible livestock management-A review. Rangeland J. 36:205-221. https://doi.org/10.1071/RJ13092.

Barrell, G. K. 2019. An appraisal of methods for measuring welfare of grazing ruminants. Front. Vet. Sci. 6:289. https://doi.org/10.3389/ fvets.2019.00289.

Bremel, R. D., and M. I. Gangwer. 1978. Effect of adrenocorticotropin injection and stress on milk cortisol content. J. Dairy Sci. 61:11031108. https://doi.org/10.3168/jds.S0022-0302(78)83693-5.

Campbell, D. L., S. Haynes, J. Lea, W. Farrer, and C. Lee. 2019a. Temporary exclusion of cattle from a riparian zone using virtual fencing technology. Animals (Basel) 9:5. https://doi.org/10.3390/ ani9010005.

Campbell, D. L., J. M. Lea, S. J. Haynes, W. J. Farrer, C. J. LeighLancaster, and C. Lee. 2018. Virtual fencing of cattle using an automated collar in a feed attractant trial. Appl. Anim. Behav. Sci. 200:71-77. https://doi.org/10.1016/j.applanim.2017.12.002.

Campbell, D. L., J. M. Lea, H. Keshavarzi, and C. Lee. 2019b. Virtual fencing is comparable to electric tape fencing for cattle behavior and welfare. Front. Vet. Sci. 6:445. https://doi.org/10.3389/fvets .2019.00445.

Campbell, D. L., J. Ouzman, D. Mowat, J. M. Lea, C. Lee, and R. S. Llewellyn. 2020. virtual fencing technology excludes beef cattle from an environmentally sensitive area. Animals (Basel) 10:1069. https://doi.org/10.3390/ani10061069. 
Chapman, D., D. Beca, J. Hill, J. Tharmaraj, J. Jacobs, and B. Cullen. 2014. Increasing home-grown forage consumption and profit in non-irrigated dairy systems. 4. Economic performance. Anim. Prod. Sci. 54:256-262. https://doi.org/10.1071/AN13186.

Clay, N., T. Garnett, and J. Lorimer. 2020. Dairy intensification: Drivers, impacts and alternatives. Ambio 49:35-48. https://doi.org/10 .1007/s13280-019-01177-y.

Dias, K., S. Garcia, M. R. Islam, and C. Clark. 2019. Milk yield, milk composition, and the nutritive value of feed accessed varies with milking order for pasture-based dairy cattle. Animals (Basel) 9:60. https://doi.org/10.3390/ani9020060.

Freire, R. 2010. Aversion learning. Pages 42-43 in The Encyclopedia of Applied Animal Behaviour and Welfare. D. S. Mills, J. N. Marchant-Forde, P. D. McGreevy, D. B. Morton, C. J. Nicol, C. J. C. Phillips, P. Sandøe, and R. R. Swaisgood, ed. CAB International.

Hemsworth, P. H., J. L. Barnett, A. J. Tilbrook, and C. Hansen. 1989. The effects of handling by humans at calving and during milking on the behaviour and milk cortisol concentrations of primiparous dairy cows. Appl. Anim. Behav. Sci. 22:313-326. https://doi.org/ 10.1016/0168-1591(89)90026-9.

Kaps, M., and W. R. Lamberson. 2009. Pages 231-271 in Biostatistics for Animal Science. 2nd ed. CAB International.

Koolhaas, J. M., S. De Boer, C. Coppens, and B. Buwalda. 2010. Neuroendocrinology of coping styles: Towards understanding the biology of individual variation. Front. Neuroendocrinol. 31:307-321. https://doi.org/10.1016/j.yfrne.2010.04.001.

Langworthy, A., M. Verdon, M. Freeman, R. Corkrey, J. L. Hills, and R. Rawnsley. 2021. Virtual fencing technology to intensively graze lactating dairy cattle I: Technology efficacy and pasture utilization. J. Dairy Sci. 104:7071-7083. https://doi.org/10.3168/jds .2020-19796.

Lee, C., I. G. Colditz, and D. L. Campbell. 2018. A framework to assess the impact of new animal management technologies on welfare: A case study of virtual fencing. Front. Vet. Sci. 5:187. https: //doi.org/10.3389/fvets.2018.00187.

Lee, C., A. D. Fisher, M. T. Reed, and J. M. Henshall. 2008. The effect of low energy electric shock on cortisol, $\beta$-endorphin, heart rate and behavior of cattle. Appl. Anim. Behav. Sci. 113:32-42. https:/ /doi.org/10.1016/j.applanim.2007.10.002.

Lee, C., K. Prayaga, M. Reed, and J. Henshall. 2007. Methods of training cattle to avoid a location using electrical cues. Appl. Anim. Behav. Sci. 108:229-238. https://doi.org/10.1016/j.applanim.2006 .12 .003 .

Lomax, S., P. Colusso, J. Gargulio, and C. Clark. 2019. Does virtual fencing work for grazing dairy cattle? Animals (Basel) 9:429. https://doi.org/10.3390/ani9070429.

McSweeney, D., B. O'Brien, N. E. Coughland, A. Ferard, S. Ivanov, P. Halton, and C. Umstatter. 2020. Virtual fencing without visual cues: Design, difficulties of implementation, and associated dairy cow behavior. Comput. Electron. Agric. 176:105613. https://doi .org/10.1016/j.compag.2020.105613.

Palme, R. 2012. Monitoring stress hormone metabolites as a useful, non-invasive tool for welfare assessment in farm animals. Anim. Welf. 21:331-337.

Quigley, T. M., H. R. Sanderson, A. R. Tiedemann, and M. L. McInnis. 1990. Livestock control with electrical and audio stimulation. Rangelands Archives 12:152-155.
Ralph, C. R., and A. Tilbrook. 2016. The usefulness of measuring glucocorticoids for assessing animal welfare. J. Anim. Sci. 94:457-470. https://doi.org/10.2527/jas.2015-9645.

Ravagnolo, O., I. Misztal, and G. Hoogenboom. 2000. Genetic component of heat stress in dairy cattle, development of heat index function. J. Dairy Sci. 83:2120-2125. https://doi.org/10.3168/jds .S0022-0302(00)75094-6.

Shutt, D. A., and L. R. Fell. 1985. Comparison of total and free cortisol in bovine serum and milk or colostrum. J. Dairy Sci. 68:1832-1834. https://doi.org/10.3168/jds.S0022-0302(85)81035-3.

Stafford, K., and N. Gregory. 2008. Implications of intensification of pastoral animal production on animal welfare. N. Z. Vet. J. 56:274-280. https://doi.org/10.1080/00480169.2008.36847.

Stookey, J. M. 2010. Fence line behavior. Page 262 in The Encyclopedia of Applied Animal Behavior and Welfare. D. S. Mills, J. N. Marchant-Forde, P. D. McGreevy, D. B. Morton, C. J. Nicol, C. J. C. Phillips, P. Sandoe, and R. R. Swaisgood, ed. CAB International.

Tasmanian Animal Welfare Act. 1993. Accessed Mar. 23, 2021. https: //www.legislation.tas.gov.au/view/html/inforce/current/act-1993 $-063$.

Termeulen, S. B., W. R. Butler, and R. P. Natzke. 1981. Rapidity of cortisol transfer between blood and milk following adrenocorticotropin injection. J. Dairy Sci. 64:2197-2200. https://doi.org/10 .3168/jds.S0022-0302(81)82829-9.

Ungar, E. D., Y. Nevo, H. Baram, and A. Arieli. 2018. Evaluation of the IceTag leg sensor and its derivative models to predict behavior, using beef cattle on rangeland. J. Neurosci. Methods 300:127-137. https://doi.org/10.1016/j.jneumeth.2017.06.001.

Verdon, M., C. Lee, D. Marini, and R. Rawnsley. 2020. Pre-exposure to an electrical stimulus primes associative pairing of audio and electrical stimuli for dairy heifers in a virtual fencing feed attractant trial. Animals (Basel) 10:217. https://doi.org/10.3390/ ani10020217.

Verdon, M., R. Rawnsley, P. Raedts, and M. Freeman. 2018. The behavior and productivity of mid-lactation dairy cows provided daily pasture allowance over 2 or 7 intensively grazed strips. Animals (Basel) 8:115. https://doi.org/10.3390/ani8070115.

Verkerk, G. A., A. M. Phipps, J. F. Carragher, L. R. Matthews, and K. Stelwagen. 1998. Characterization of milk cortisol concentrations as a measure of short-term stress response in lactating dairy cows. Anim. Welf. 7:77-86.

Verkerk, G. A., A. M. Phipps, and L. R. Matthews. 1996. Milk cortisol concentrations as an indicator of stress in lactating dairy cows. Pages 77-79 in Proceedings of the New Zealand Society of Animal Production Vol. 56.

Werner, J., L. Leso, C. Umstatter, J. Niederhauser, E. Kennedy, A. Geoghegan, L. Shalloo, M. Schick, and B. O'Brien. 2018. Evaluation of the RumiWatchSystem for measuring grazing behavior of cows. J. Neurosci. Methods 300:138-146. https://doi.org/10.1016/ j.jneumeth.2017.08.022.

\section{ORCIDS}

Megan Verdon ( https://orcid.org/0000-0002-3971-4161 Adam Langworthy @ https://orcid.org/0000-0003-1203-7268 